\title{
UNIVERSITY EDUCATION IN ADDITIVE MANUFACTURING AND THE NEED TO BOOST DESIGN ASPECTS
}

\author{
Borgianni, Yuri (1); Maccioni, Lorenzo (1); Russo Spena, Pasquale (1); Shunmugavel, \\ ManikandaKumar (1,2) \\ 1: Free University of Bolzano-Bozen, Faculty of Science and Technology, Bolzano, Italy; 2: School of \\ Engineering, Faculty of Science, Engineering and Built Environment, Deakin University, Victoria, \\ Australia
}

\begin{abstract}
Additive Manufacturing (AM) is a potentially revolutionary technique in industry with claims of high skills shortage in the recent days. It is assumed that full exploitation of AM capabilities can be made possible by a paradigm shift steered by engineering design. Future generations of engineers might benefit from Design for Additive Manufacturing (DfAM), which targets AM potential and enables design freedoms. In this context, the paper investigates AM education for a better understanding of the main AM-related subjects taught in universities. To this scope, the authors gathered 52 syllabi of courses taught in highly-ranked technical universities worldwide that relate to AM. From the investigation, it emerges that AM is the core discipline of the course in 42 out of 52 cases and considered widely as an independent domain to date. As for taught subjects, it was found that design aspects in AM and DfAM are poorly focused on, while manufacturing and process areas are the most popular. This poses a challenge especially to the design community, as the current situation might limit the exploitation of AM capabilities.
\end{abstract}

Keywords: Design for Additive Manufacturing (DfAM), Design education, Computer Aided Design (CAD), Additive Manufacturing

\section{Contact:}

Borgianni, Yuri

Free University of Bolzano-Bozen

Faculty of Science and Technology

Italy

yuri.borgianni@unibz.it

Cite this article: Borgianni, Y., Maccioni, L., Russo Spena, P., Shunmugavel, M. (2019) 'University Education in Additive Manufacturing and the Need to Boost Design Aspects', in Proceedings of the 22nd International Conference on Engineering Design (ICED19), Delft, The Netherlands, 5-8 August 2019. DOI:10.1017/dsi.2019.67 


\section{INTRODUCTION}

Additive Manufacturing (AM) or 3D Printing is a potentially revolutionary manufacturing process of fabricating three-dimensional objects by addition of material layers based on a 3D CAD model. Various materials such as plastics, metals, ceramics and composites are being widely used to create complex 3D products (Bourell et al., 2017). In addition to the wide range of materials that can be fabricated using this technology, it also offers various advantageous features such as: a) on-demand manufacturing, b) batch production, c) design freedom and d) low material wastage (Attaran, 2017). As a result, additive manufacturing is widely preferred in aerospace, biomedical, automotive, defence, fashion, entertainment and various other industries enjoying business benefits (Gibson et al., 2010; Bourell et al., 2014). According to the 2018 Wohlers Associates' report, the AM industry grew about $21 \%$ in 2017 compared to the $17.4 \%$ growth in the previous year (2016). Moreover, the global value of AM products and services is still expected to grow considerably from \$ 4 billion in 2015 to $\$ 10.8$ billion in 2021 according to the report. It is strongly believed that AM can transform the way items are manufactured, traditional business models, established supply chains and economics of where, how and when things are made (Beyer, 2014).

The rapid growth and emergence of AM and 3D printing technologies is introducing skills shortage in industries and this requires the design of effective educational programs and courses to train students and professionals to meet the increasing demand of AM designers and engineers in today's industry (Ford and Minshall, 2018). Actually, at the current stage, AM or 3D printing is widely used in teaching and education: to train students about 3D printing technologies; to teach educators about 3D printing technology; as a supportive technology during teaching; to produce artefacts that aid learning; to create assistive technologies and to support outreach activities (Ford and Minshall, 2018). However, still according to (Ford and Minshall, 2018), there is a need for additional teaching and curricula materials to improve student engagement and subject knowledge acquisition. This stance is supported by Violante and Vezzetti (2017), who still believe that educational efforts in the emerging advanced manufacturing technologies lag behind the required technical competencies in the industrial sector this results in increasing the skills shortage despite numerous initiatives to support the use of AM in educational programs. Present deficiencies of AM gaps do not concern the engineering domain only, as highlighted in the followings.

Beyer (2014) stated that educators must understand the transformative nature of the AM technologies and alter curricula emphasizing its importance over the subtractive process. Gatto et al. (2015) found that the soon-to-be engineers will need new practice-oriented capabilities to cope with new competitive scenarios and thus engineering education must adapt to the social rather than industrial, revolution that is being brought about by additive fabrication. Ford and Dean (2013) stated that AM should be taught alongside with existing manufacturing technologies in a commercial context so that students can balance cost-effectiveness, scales of production and the new opportunities in emerging markets for niche AM products.

However, the potential implications of AM in the design field is undoubtedly one of the most overlooked aspects in education, especially if opportunities are considered contextually. Anthony et al. (2011) suggest that design curricula explore the use of AM technologies through collaborative engagement upon real-world projects. Campbell et al. (2012) discuss that the embedding of AM in design curricula, workshops and on-line training resources at university and professional level will enable designers to realise the unique features of AM by ignoring the traditional "design for manufacturing" limitations. While discussing about AM education in his paper, Rosen (2014) highlights how AM uniqueness might have the most significant repercussions and opportunities in engineering design. Minetola et al. (2015) claim that the full exploitation of AM technology can be achieved by early exposure of forthcoming designers to AM tools to turn them in to a "think additive" approach to product design, which is a ground-breaking conception of geometries and product functionalities. Realising the educational needs in AM, Simpson et al. (2017) recommend that AM curricula provide students with capabilities concerning, among the others, Design for Additive Manufacturing (DfAM), which, in turn, should include computational tools for AM design as well as frameworks for process selection, costing and solution generation. Ferchow et al. (2018) believe that engineers in industry have little or no experience in DfAM and an integrated experience transfer in engineering education is not yet widespread. The benefits of presenting AM and design concepts in 
parallel are made evident in some experiences. For instance, Junk and Schrock (2016) found that a workshop on Rapid Prototyping (RP) focussing on conveying technical and creative knowledge for product development in AM with a hand-on approach for students significantly expanded their theoretical and practical knowledge.

The present paper is concerned with the verification of the actual emphasis on AM-related design aspects and DfAM in different universities in the world to understand the progress of AM education. From the literature review of AM-related education (Section 2), it was found that many contributions describe educational experience and draw reflections as a consequence. However, it emerges that no standard framework for AM education is adapted so far. Therefore, in order to cope with the paper's research objective, an investigation of University courses including AM-related topics has been performed (Section 3). This has made it possible to identify the most popular areas in AM education (Section 4). The outcomes of the study are then discussed in Section 5, while limitations and final remarks are to be found in Section 6.

\section{STATE OF THE ART}

The present section is devoted to reviewing the literature with regard to AM education, its benefits and limitations.

AM has introduced drastic changes and developments in the industrial world, and this should have an influence on current education curricula at schools and universities (Ramirez-Mendoza et al., 2018). Consequently, major initiatives were undertaken in AM education to address the misalignment between available qualifications and industrial needs. For instance, the US Defence Advanced Research Projects Agency sponsored a MENTOR program for up to 1000 schools with a web-based design and manufacturing infrastructure. It integrated CAD, CAE, design-for-manufacturing and CAM software tools with a network of 3D printers and other manufacturing resources to educate and train students about collaborative design, advanced manufacturing and new product development practices, motivating them about pursuing technology-based careers (Rosen et al., 2012). However, as already underlined in the Introduction, the efforts paid so far are not sufficient to address the current challenge.

Go and Hart (2016) found that AM while rooted in mechanical engineering and materials science is truly multidisciplinary and education programs should be tailored and designed based on the audiences. In addition, they also found that project-based AM course with clear scope and goals helped secure collaborative industrial research with financial support, whereas the use of digitally archived content on $\mathrm{AM}$ and related topics helped students of diverse academic backgrounds to adapt to the curriculum. Similarly, it was reported that project-based AM courses which involved the students to design, manufacture and assemble additive manufactured components yielded excellent student learning outcomes, experiences and satisfaction on the course (Mo and Tang, 2017; Williams and Seepersad, 2012; Lindley, 2014; Pieterse and Nel, 2016; Ferchow et al., 2018). Williams and Seepersad (2012) designed an AM course, which received positive feedback from the students, based on inductive instructional approach by presenting students with challenging problems (Problem-based Learning) and open-ended projects (Project-based Learning) alongside with opportunities to learn experimental skills, mirror professional practice and build and test designs. Meyers et al. (2016) found that introducing 3D printing in a cornerstone project increased the interest level, project relevance, learning levels and experience with the design process providing a meaningful and effective approach to introduce design process to the engineering students. The increased student satisfaction and experience can be attributed to the fact that the students finally created a tangible product using AM, whereas in the earlier days it was limited to product conceptualisation, virtual modelling and simulation (Geraedts et al., 2012).

However, the multidisciplinary aspects of AM in different industries poses challenges in student learning and the ability to use this technology to create end components effectively. For instance, in designing medical components using 3D printing technology, the students struggled as they had no prior knowledge on anatomy and physiology (Mirtaheri et al., 2017). Harvey (2016) believed that short courses in AM provide only a cursory coverage of engineering principles and the need for an introductory subject combining both a solid academic grounding and practical experience is imperative. Junk and Matt (2015) developed two new approaches, namely a) workshops for the students to assemble and install 3D printers that enabled them to realise the functionalities of AM and the creative possibilities and limits of this process and b) the combination of reverse engineering and 3D printing to teach design of 3D-printed components and to enable them to deal with complex process chain. 
Efforts have been made also in terms of favouring the diffusion of educational material. Kai Chua et al. (2010) designed and developed a RP multimedia courseware for academicians, engineers and marketing personnel, which allows the users to learn, visualize and evaluate different RP systems and their applications without the aid of any physical hardware. Despite available AM education resources and training materials, there is no proven model for AM education and training and the current workforce and future workforce needs to be skilled to develop design tools, effectively amend and improve verification and validation procedures to take the full advantage of AM (Huang et al., 2015). Further development is also necessary in topics such as AM design communication, costing and enterprise - level design decisions and AM design methodologies (Huang et al., 2015).

Overall, there are a number of research articles discussing "how to implement AM effectively in engineering education" and "what are the outcomes of project based/practical approaches in AM courses". However, there is still a knowledge gap on understanding "what AM topics are taught around the universities in the world". This research is therefore undertaken to comprehensively understand the focus areas of the AM courses taught in tertiary education with specific focus and priority for top universities in the world.

\section{RESEARCH PROCEDURE}

The main methodological objective was to collect information on courses that include AM-related contents, as they reflect future trainees' skills. Therefore, a sample of courses was created to conduct the investigation. AM courses are taught in a large number of Universities worldwide, therefore a priority criterion had to be established. As per the criteria, AM courses taught only in tertiary educational institutions belonging to high-ranking positions in the Quacquarelli Symonds World University Ranking in the field of Engineering \& Technology were considered and studied. Here, it was believed that Universities with a considerable reputation might affect the knowledge of future engineering and technicians to a large extent. The ranking was accessed on November 1st, 2018 at the webpage https://www.topuniversities.com/. In the search strategy, the University web portals were first identified, e.g. mit.edu. Then, for the screening of AM related courses, the following search queries were used in Google, which makes it possible to individuate webpages that include the used search terms wherever in the webpages (not necessarily in the title of the webpage):

- site:webportal "additive manufacturing"

- site:webportal "3D printing"

- $\quad$ site:webportal "rapid prototyping".

The search provided results about research groups, papers, workshops or other activities, but this information was irrelevant for the purpose of the study and was ignored. The search revealed that a small number of the investigated Universities offer (or are planning to offer) complete study programs on AM or RP, namely Pennsylvania State University, Carnegie Mellon University, Ohio State University (in the USA), Monash University (Australia) and Politecnico di Torino (Italy).

The identified courses including an English-written description or syllabus were included in the sample. The strings used to identify courses were not necessarily parts of the name of the course - the introduction of AM-related contents was the sole criterion for inclusion. Both courses intended for enrolled students and the public, e.g. those mainly addressed to managers and industrialists, were considered pertinent for the research. The entire process was followed consistently until 50 courses were identified; the final sample comprises 52 courses (see Table 1), as the last University scrutinized allowed the individuation of a large number of courses.

Table 1. Sample of analysed courses including their names and respective institutions

\begin{tabular}{|l|l|c|}
\hline No. & Name of the course & Institution \\
\hline 1. & $\begin{array}{l}\text { Additive Manufacturing for Innovative Design and } \\
\text { Production }\end{array}$ & MIT \\
\hline 2. & $\begin{array}{l}\text { Additive Manufacturing: From Prototyping to } \\
\text { Production }\end{array}$ & MIT \\
\hline 3. & Rapid Prototyping technology & MIT \\
\hline 4. & Engineering Design and Rapid Prototyping & Stanford \\
\hline 5. & $\begin{array}{l}\text { Additive Manufacturing: From Fundamentals to } \\
\text { Applications }\end{array}$ & \\
\hline
\end{tabular}




\begin{tabular}{|c|c|c|}
\hline 6. & Graduate certificate in Additive Manufacturing & NUS Singapore \\
\hline 7. & 3D Printing and Additive Manufacturing & $\begin{array}{c}\text { Nanyang Technological University } \\
\text { Singapore }\end{array}$ \\
\hline 8. & Digital Manufacturing & TU Delft University of Technology \\
\hline 9. & Digital Manufacturing for Industrial Design & TU Delft University of Technology \\
\hline 10. & Level 1/2 Certification Additive Manufacturing & Purdue University \\
\hline 11. & $\begin{array}{l}\text { From Additive Manufacturing to Field-Assisted } \\
\text { Sintering - 1 Road Towards New Discoveries }\end{array}$ & $\begin{array}{l}\text { Ecole Polytechnique Federale de } \\
\text { Lasusanne }\end{array}$ \\
\hline 12. & $\begin{array}{l}\text { Additive Manufacturing of Polymeric Materials - 3D } \\
\text { Camp }\end{array}$ & $\begin{array}{l}\text { Ecole Polytechnique Federale de } \\
\text { Lasusanne }\end{array}$ \\
\hline 13. & $\begin{array}{l}\text { Additive Manufacturing of Metals and the Material } \\
\text { Science Behind it }\end{array}$ & $\begin{array}{l}\text { Ecole Polytechnique Federale de } \\
\text { Lasusanne }\end{array}$ \\
\hline 14. & Introduction to Additive Manufacturing & $\begin{array}{l}\text { Ecole Polytechnique Federale de } \\
\text { Lasusanne }\end{array}$ \\
\hline 15. & Advanced Additive Manufacturing Technologies & $\begin{array}{l}\text { Ecole Polytechnique Federale de } \\
\text { Lasusanne }\end{array}$ \\
\hline 16. & Advanced CAD Modelling and Rapid Prototyping & KTH Royal Institute of Technology \\
\hline 17. & Introduction to Additive Manufacturing & North Western University \\
\hline 18. & Rapid Prototyping & North Western University \\
\hline 19. & Practical course Additive Manufacturing & Technical University of Munich \\
\hline 20. & Casting and Rapid Prototyping & Technical University of Munich \\
\hline 21. & Advanced concepts in metals & University of Melbourne \\
\hline 22. & Capstone Design Project Course (CDPC) & $\begin{array}{c}\text { Tokyo Institute of Technology and } \\
\text { Taiwan Tech }\end{array}$ \\
\hline 23. & Additive Manufact & UNSW Sydney \\
\hline 24. & Nano and Microscale Rapid Prototyping Manufacture & Cranfield University \\
\hline 25. & Metal Additive Manufacturing & Cranfield University \\
\hline 26. & Advanced Manufacturing Technologies & University of Toronto \\
\hline 27. & Computer Aided Design and Manufacturing & $\begin{array}{l}\text { Hongkong University of Science } \\
\text { and Technology }\end{array}$ \\
\hline 28. & Manufacturing Process and Systems & $\begin{array}{l}\text { Hongkong University of Science } \\
\text { and Technology }\end{array}$ \\
\hline 29. & Computer Aided product development (CAPD) & The University of Hong Kong \\
\hline 30. & $\begin{array}{l}\text { Additive Manufacturing using Metallic and Ceramic } \\
\text { Materials }\end{array}$ & McGill University \\
\hline 31. & Product Design & McGill University \\
\hline 32. & Additive Manufacturing and 3D Product Modelling & University of Manchester \\
\hline 33. & Foundations of Creative Code & The Australian National University \\
\hline 34. & Discovering Engineering & The Australian National University \\
\hline 35. & $\begin{array}{l}\text { Form and Fabrication in Context/Digital Form and } \\
\text { Fabrication }\end{array}$ & The Australian National University \\
\hline 36. & $\begin{array}{l}\text { Introduction to Computer Aided Design (CAD) and 3D } \\
\text { Printing }\end{array}$ & Brown University \\
\hline 37. & Additive Manufacturing designated minor & Carnegie Mellon University \\
\hline 38. & $\begin{array}{l}\text { Additive Manufacturing Processing and Product } \\
\text { Development }\end{array}$ & Carnegie Mellon University \\
\hline 39. & Advanced Manufacturing Technologies & City University of Hong Kong \\
\hline 40. & Digital Manufacturing & Columbia University \\
\hline 41. & Introduction to 3D Printing & Duke University \\
\hline 42. & Additive Manufacturing & Johns Hopkins University \\
\hline 43. & Additive Manufacturing Processes - 3D Printing & KU Leuven \\
\hline 44. & Design for Additive Manufacturing & Politecnico di Torino \\
\hline
\end{tabular}




\begin{tabular}{|l|l|c|}
\hline 45. & Materials for Additive Manufacturing & Politecnico di Torino \\
\hline 46. & Additive Manufacturing Systems & Politecnico di Torino \\
\hline 47. & $\begin{array}{l}\text { Advanced Sensors for the control of Additive } \\
\text { Manufacturing Systems }\end{array}$ & Politecnico di Torino \\
\hline 48. & $\begin{array}{l}\text { Integration of Additive Manufacturing Technologies } \\
\text { with conventional processes for parts finishing }\end{array}$ & Politecnico di Torino \\
\hline 49. & $\begin{array}{l}\text { Systems for the evaluation of products made using } \\
\text { additive manufacturing }\end{array}$ & Politecnico di Torino \\
\hline 50. & $\begin{array}{l}\text { Production management in Additive Manufacturing } \\
\text { systems }\end{array}$ & Politecnico di Torino \\
\hline 51. & $\begin{array}{l}\text { Supply chain management in Additive Manufacturing } \\
\text { systems }\end{array}$ & Politecnico di Torino \\
\hline 52. & $\begin{array}{l}\text { ICT platforms for facilitating the integration of additive } \\
\text { manufacturing in traditional manufacturing process }\end{array}$ & \\
\hline
\end{tabular}

The extracted course information was carefully studied to extract crucial data for the study. In particular, the following information was considered critical by the authors.

1. The main topic of the courses, as AM-related contents can be taught in the framework of different subjects (Section 4.1), e.g. in an engineering design course.

2. The AM-related subjects that are clearly identifiable in the syllabi or descriptions (Section 4.2).

3. The fields of application for AM technologies that are reported (Section 4.3).

\section{RESULTS OF THE COURSES' INVESTIGATION}

\subsection{Courses' topics}

AM can be taught as an independent topic or in the framework of other disciplines. Therefore, the list of these related disciplines was initially hypothesized and then adjusted based on outcomes; for instance, the category "robotics \& automation" was eventually removed due to the absence of pertinent courses. From the investigation, it was found that AM is taught as an independent discipline in 42 out of the 52 surveyed courses. The main topic of the residual 10 courses can be visualized in Figure 1 as grey portions of columns where design plays the most relevant role. In a number of cases (white portions of columns), AM is the main focus of the course together with other disciplines, diffusedly manufacturing and CAD.

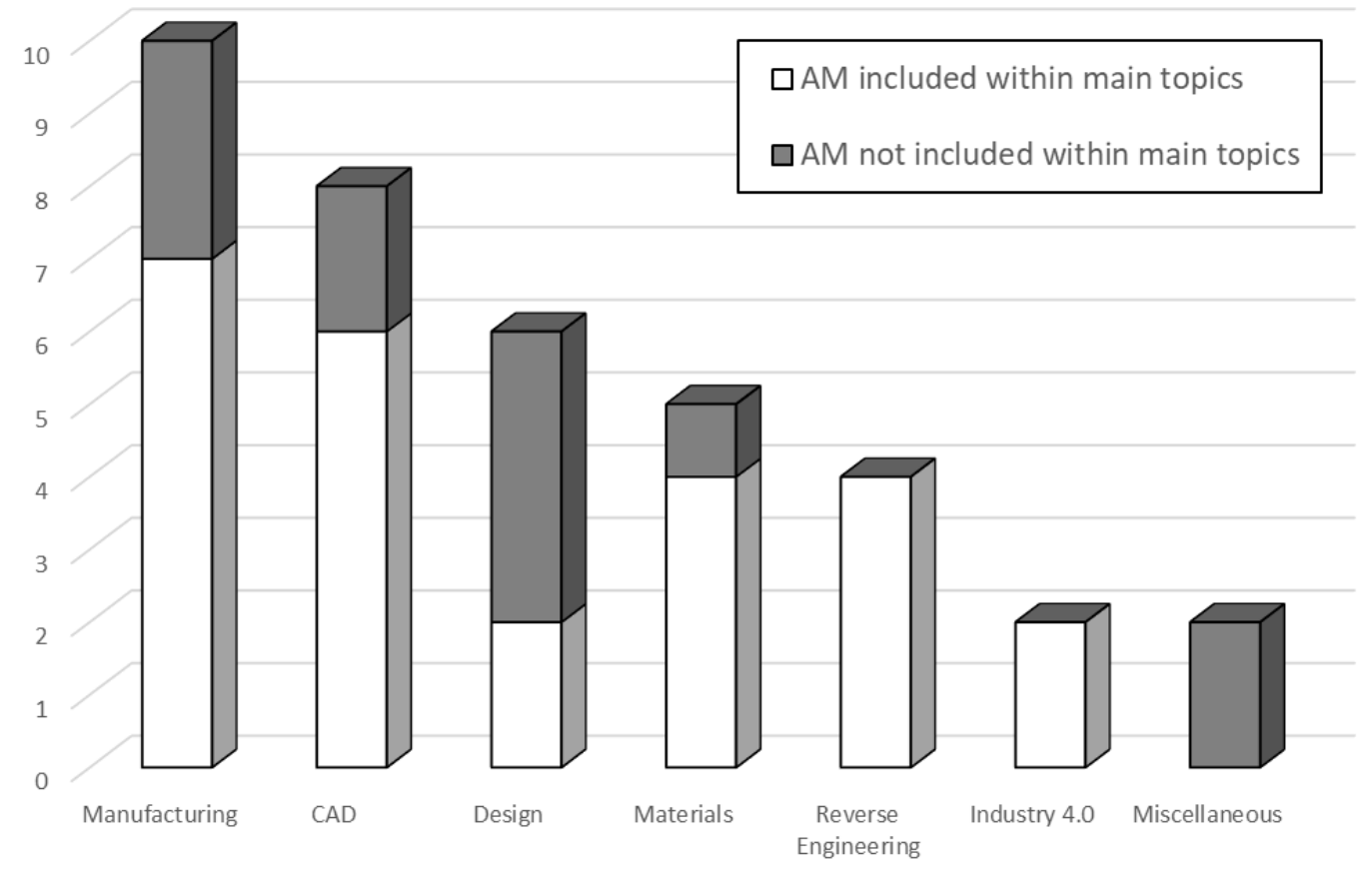

Figure 1. Number of selected courses including AM-related contents whose core topic (other than AM) is indicated in the abscissa. 


\subsection{Focused subjects within additive manufacturing}

In order to categorize which contents are illustrated to courses' participants, the authors have hypothesized an initial classification, which has been further refined based on the extracted information. The association between courses and contents has been made by the authors - the descriptions of classes below have been used as guidelines for the categorization. The final classes have been further grouped into three main groups, as visible in Figure 2 and better explained below. The second-level bullet points are ordered like the AM-related subjects presented in the abscissa of Figure 2.

- Aspects concerning technologies and processes involved in AM.

$\circ$ Description of different technologies belonging to the AM framework, e.g. stereolithography, Fused Deposition Modelling, Selective Laser Sintering.

- Illustration of non-AM technologies used for RP, e.g. laser cutting, multi-axis milling.

- Focus on comparisons between AM and traditional technologies, description of their pros and cons.

- Illustration of techniques that combine $\mathrm{AM}$ and traditional manufacturing technologies, e.g. rapid tooling.

- Use and development of cutting-edge AM technologies, use of AM for printing electronic components and sensors, 4D printing, multi-material AM.

- Focus on the processes that characterize the use of AM, including the .STL transformation of the CAD model, the slicing process, the setting of printing parameters, the possible exploitation of Reverse Engineering acquisitions.

- Illustration of the various materials used in AM technologies, their mechanical, structural and microstructural properties.

- Design-related aspects.

- Use of AM technologies to support the design and product development process, e.g. RP, its benefits.

- DfAM, design freedoms enabled by AM, heuristics, rules and guidelines for the use of AM to fabricate products effectively.

- Illustration of Topology Optimization in relation to AM capabilities.

- CAD issues in relation to AM, specific CAD systems to fully exploit AM capabilities.

- $\quad$ Repercussions of the introduction and diffusion of AM.

- Business implications, e.g. in terms of costs, times, new business models and impacts on the supply chain.

○ Diffusion of Fablabs, maker spaces, the Do-it-Yourself movement, non-industrial uses of AM technologies.

- $\mathrm{AM}$ as an enabling technology and a support for Industry 4.0 and digitalisation.

- Illustration of research trends in AM.

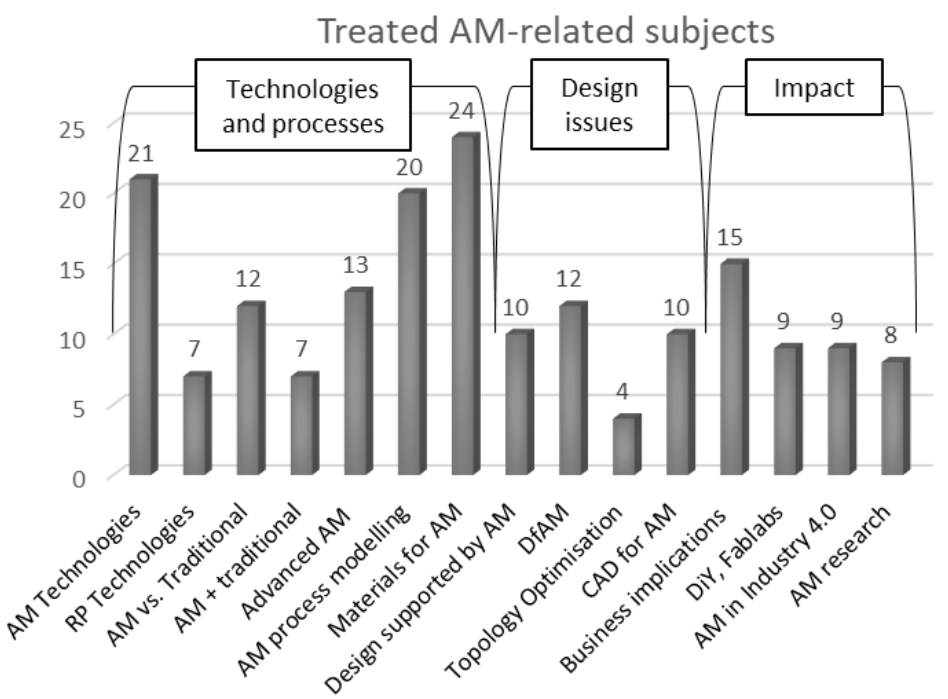

Figure 2. Number of courses that treat the subjects in the abscissas within AM; the subjects are grouped according to a) technological, material and process aspects, b) design-related aspects, c) implications and impacts in industry, research and society at large. 


\subsection{Application fields for additive manufacturing}

Eventually, the authors have noticed that many courses' syllabi include reference to applications. To this respect, the fields of these applications have been monitored (Figure 3) in order to provide a better understanding of the favourite outlets of AM-ed products and prototypes. No direct reference to education was found.

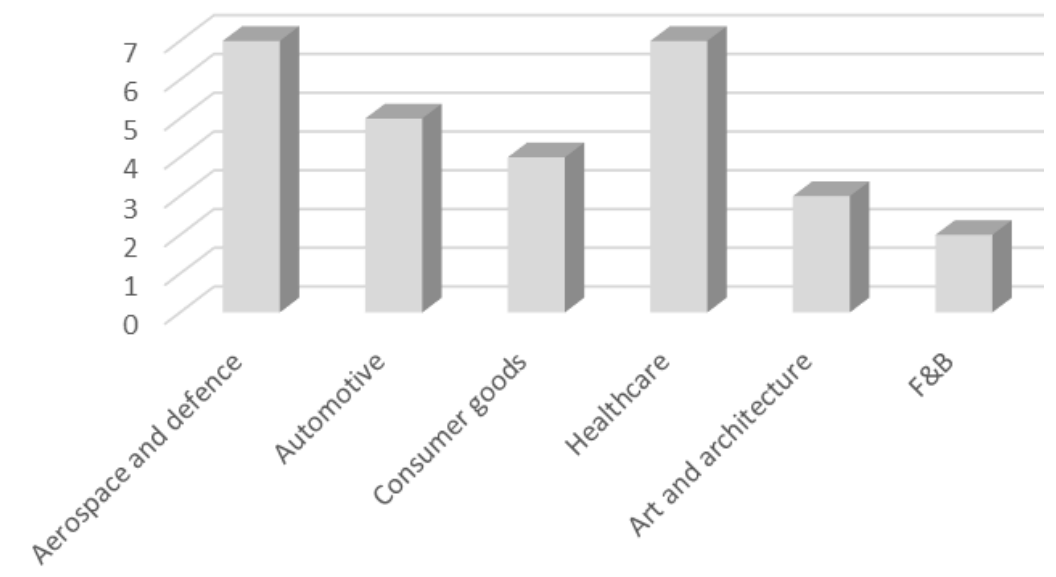

Figure 3. Number of courses that include illustrative applications of AM technologies in the fields indicated in the abscissa.

\section{DISCUSSION}

The results of the present investigation suggest that AM is to date established as an independent discipline in the educational context of technical universities. This is confirmed by a number of programs and specializations markedly oriented to AM teaching. In light of the centrality of AM in the monitored courses, it seems that the recalled need to push the diffusion of AM-related contents in industry and academia is not neglected.

On the other hand, while the literature agrees on priority to be assigned to the understanding of AM repercussions in design, design-related topics are overshadowed in a significant number of courses. To this respect, it is worth noting that subjects like DfAM present a lower number of entries in Figure 2 than AM technologies and materials, and business aspects related to AM - the latter might sound surprising, as the investigation was performed within courses taught at technical institutions. Likewise, limitations of mainstream CAD systems with regard to the design of geometries taking advantage of AM freedoms and the development of more suitable ones are rarely in focus in the monitored courses. Results shown in Figure 2 along with authors' interpretation indicate how AM teaching often concentrates on process-related aspects and the illustration of AM as a set of alternative technologies with repercussions in terms of followed procedures and employed materials. Nevertheless, the necessary explanation of technological aspects does not regularly cross the manufacturing domain showing how changes induced by AM might affect design.

As aforementioned, it is assumed that the benefits enabled by AM can be completely exploited just by stressing AM-enabled freedoms during design. This requires a change of mind-set for designers and engineers and, therefore, education of next generations plays a relevant role. According to this reading and in consideration of the results, it emerges how the paradigm shift made possible by AM will be unlikely fully enjoyed in the years to come.

The misalignment between the importance of design-related aspects and their assessed relevance in AM education can give rise to different explanations. On the one hand, while the first AM technologies date back to the mid-1980s, research on how these technologies might modify design cycles has started much later - the term DfAM is firstly found in the first decade of the 2000s on a Scopus-indexed publication. On the other hand, AM has long been considered in design as a facilitating technology for RP and just more recently its potential for end-use products has been explored. This means that, in many cases, the parts to be prototyped with AM should be designed for a final large-scale fabrication with conventional technologies. As for the application fields of AM, it is worth remarking how courses from technical universities do not limit their examples to traditional engineering domains. The (unsurprising) relevance of the healthcare 
sector, among the others, supports the necessity to reconsider traditional disciplinary boundaries, which AM contributes to fuel as suggested in Section 2.

\section{CONCLUSIONS}

The present work is motivated by the increasing interest on AM shown by the industrial world, whose qualification needs are not sufficiently met by educational institutions. Contextually, the literature claims that the key to an effective exploitation of the benefits made available by AM might take place if AMenabled design freedoms are understood by a large audience. Hence, the acquisition of DfAM concepts by new generations of engineers is attributed of paramount importance. In this framework, the scope of the paper provides an overview on what is actually taught in relation to AM as this has not been analysed in the literature in a structured and comprehensive way. Detailed analysis from the sample of University-level courses related to AM subjects gathered by the authors reveal that, most of the courses include AM as a core topic and that manufacturing aspects are presented more diffusedly rather than the design-related issues. Therefore, the sharing of knowledge about DfAM lags significantly behind process aspects. To this respect, the design community is urged to provide its contribution to make these contents more widely and easily available.

In any case, the results are affected by some limitations worth being considered by readers.

- The sample of syllabi and courses description is limited in number. Future work will be necessary to enlarge the sample and check to which extent expansions will impact on the above considerations.

- Many courses were discarded because insufficient information was available.

- All the classifications presented in Section 4 are made by the authors and suffer from a certain degree of subjectivity although some criteria have been established to make the categorization more robust.

- The contents taught at top-rated technical universities might not mirror those divulgated at a larger scale.

- The authors relied on information found in courses' syllabi and descriptions, but these could partially differ from what is actually taught in class.

The authors are available to share full details about the gathered courses' descriptions and the classification performed accordingly.

\section{REFERENCES}

Anthony, R. W., Evans, M., Rennie, A. E. W. and Kirkby, E., (2011), “Opportunities offered by additive manufacturing in creative businesses: informing designers". In DS 69: Proceedings of E \& PDE 2011, the 13th International Conference on Engineering and Product Design Education, London, UK, 08-09 September 2011.

Attaran, M. (2017), "The rise of 3-D printing: the advantages of additive manufacturing over traditional manufacturing”. Business Horizons, Vol. 60, pp. 677-688. http://dx.doi.org/10.1016/j.bushor.2017.05.011

Beyer, C. (2014), "Strategic implications of current trends in additive manufacturing", Journal of Manufacturing Science and Engineering, Vol. 136, p. 064701. http://dx.doi.org/10.1115/1.4028599

Bourell, D., Kruth, J. P., Leu, M., Levy, G., Rosen, D., Beese, A. M. and Clare, A. (2017), "Materials for additive manufacturing", CIRP Annals, Vol. 66, pp. 659-681. http://dx.doi.org/10.1016/j.cirp.2017.05.009

Bourell, D. L., Rosen, D. W. and Leu, M. C. (2014), "The roadmap for additive manufacturing and its impact", 3D Printing and Additive Manufacturing, Vol. 1, pp. 6-9. https://doi.org/10.1089/3dp.2013.0002

Campbell, I., Bourell, D. and Gibson, I. (2012), “Additive manufacturing: rapid prototyping comes of age”, Rapid prototyping journal, Vol. 18, pp. 255-258. http://dx.doi.org/10.1108/13552541211231563

Ferchow, J. F., Klahn, C. and Meboldt, M. (2018), "Enabling graduated students to design for additive manufacturing through teaching and experience transfer", DS 93: Proceedings of the 20th International Conference on Engineering and Product Design Education (E \& PDE 2018), Dyson School of Engineering, Imperial College, London. 6th-7th September 2018, 2018. pp. 199-204.

Ford, P. and Dean, L. (2013), "Additive manufacturing in product design education: out with the old and in with the new?”, DS 76: Proceedings of E \& PDE 2013, the 15th International Conference on Engineering and Product Design Education, Dublin, Ireland, 05-06 September 2013. pp. 611-616.

Ford, S. and Minshall, T. (2018), "Invited Review Article: Where and how 3D printing is used in teaching and education", Additive Manufacturing. http://dx.doi.org/10.1016/j.addma.2018.10.028

Gatto, A., Bassoli, E., Denti, L., Iuliano, L. and Minetola, P. (2015), "Multi-disciplinary approach in engineering education: learning with additive manufacturing and reverse engineering", Rapid Prototyping Journal, Vol. 21, pp. 598-603. http://dx.doi.org/10.1108/RPJ-09-2014-0134 
Geraedts, J., Doubrovski, E., Verlinden, J. and Stellingwerff, M. (2012), “Three views on additive manufacturing: business, research and education”. Ninth Int. Symp. Tools Methods Compet. Eng., I. Horváth, A. Albers, M. Behrendt and Z. Rusák, Eds, 2012. pp. 1-15.

Gibson, I., Rosen, D. W. and Stucker, B. (2010), "Design for additive manufacturing”, In Additive Manufacturing Technologies, pp. 299-332. Springer, Boston, MA. http://dx.doi.org/10.1007/978-1-4419-1120-9_11.

Go, J. and Hart, A. J. (2016), "A framework for teaching the fundamentals of additive manufacturing and enabling rapid innovation", Additive Manufacturing, Vol. 10, pp. 76-87. http://dx.doi.org/10.1016/j.addma.2016.03.001

Harvey, S. (2016), "Teaching additive manufacturing in a higher education setting", 27th Annual Conference of the Australasian Association for Engineering Education: AAEE 2016. Southern Cross University, pp. 329-336.

Huang, Y., Leu, M. C., Mazumder, J. and Donmez, A. (2015), “Additive manufacturing: current state, future potential, gaps and needs, and recommendations", Journal of Manufacturing Science and Engineering, vol. 137, p. 014001. http://dx.doi.org/10.1115/1.4028725

Junk, S. and Matt, R. (2015), "New approaches to teaching design for additive manufacturing", DS 80-11 Proceedings of the 20th International Conference on Engineering Design (ICED 15) Vol 11: Human Behaviour in Design, Design Education, Milan, Italy, 27-30 July 2015.

Junk, S. and Schrock, S. (2016), "New developments in design education for additive manufacturing", DS 83 : Proceedings of the 18th International Conference on Engineering and Product Design Education (E and PDE16), Design Education: Collaboration and Cross-Disciplinarity, Aalborg, Denmark, 8th-9th September 2016.

Kai Chua, C., Fai Leong, K., Sing Lim, C. and Thien Vu, T. (2010), "Multimedia courseware for teaching of rapid prototyping systems", Rapid prototyping journal, Vol. 16, pp. 80-89. http://dx.doi.org/10.1108/13552541011025807

Lindley, J., Adams, R., Beaufoy, J. and McGonigal, S. (2014), “A Traditional Approach to 3D Printing”, In DS 78: Proceedings of the 16th International conference on Engineering and Product Design Education (E and PDE14), Design Education and Human Technology Relations, University of Twente, The Netherlands, 04-05 September 2014, pp. 555-560.

Meyers, K. L., Morgan, A. S. and Conner, B. P. (2016), "3D printing to introduce design in a cornerstone project", Global Journal of Engineering Education, Vol. 18, pp. 22-29.

Minetola, P., Iuliano, L., Bassoli, E. and Gatto, A. (2015), "Impact of additive manufacturing on engineering education-evidence from Italy”, Rapid Prototyping Journal, Vol. 21, pp. 535-555. http://dx.doi.org/10.1108/RPJ-09-2014-0123

Mirtaheri, P., Guler, E. and Gjřvaag, T. (2017), “3D printing in medical application: an educational design perspective", DS 88: Proceedings of the 19th International Conference on Engineering and Product Design Education (E and PDE17), Building Community: Design Education for a Sustainable Future, Oslo, Norway, 78 September 2017. pp. 176-181.

Mo, J. P. and Tang, Y. (2017), "Project-based learning of systems engineering V model with the support of 3D printing", Australasian Journal of Engineering Education, Vol. 22, pp. 3-13. http://dx.doi.org/10.1080/22054952.2017.1338229

Pieterse, F. and Nel, A. L. (2016), "The advantages of 3D printing in undergraduate mechanical engineering research", 2016 IEEE Global Engineering Education Conference (EDUCON). IEEE, pp. 25-31. http://dx.doi.org/10.1109/educon.2016.7474526

Ramirez-Mendoza, R. A., Morales-Menendez, R., Iqbal, H. and Parra-Saldivar, R. (2018), "Engineering Education 4.0:-proposal for a new Curricula", In Global Engineering Education Conference (EDUCON), 2018 IEEE, pp.1273-1282. http://dx.doi.org/10.1109/educon.2018.8363376

Rosen, D. W. (2014), “Design for Additive Manufacturing: Past, Present, and Future Directions”, Journal of Mechanical Design, Vol. 136, p. 090301. http://dx.doi.org/ 10.1115/1.4028073

Rosen, D. W., Schaefer, D. and Schrage, D. (2012), "GT MENTOR: A high school education program in systems engineering and additive manufacturing”, 23rd Annual International Solid Freeform Fabrication SymposiumAn Additive Manufacturing Symposium (SFF 2012). University of Bath.

Simpson, T. W., Williams, C. B. and Hripko, M. (2017), "Preparing industry for additive manufacturing and its applications: Summary and recommendations from a National Science Foundation workshop", Additive Manufacturing, Vol. 13, pp. 166-178. http://dx.doi.org/10.1016/j.addma.2016.08.002

Violante, M. G. and Vezzetti, E. (2017), "Guidelines to design engineering education in the twenty-first century for supporting innovative product development”, European Journal of Engineering Education, Vol. 42, pp. 1344 1364. http://dx.doi.org/10.1080/03043797.2017.1293616

Williams, C. B. and Seepersad, C. C. (2012), "Design for additive manufacturing curriculum: A problem-and projectbased approach", International solid freeform fabrication symposium, 2012. Austin, TX, pp. 81-92.

\section{ACKNOWLEDGMENTS}

The research is supported by the project AMDAPA, funded by the Free University of Bozen-Bolzano with the call CRC2016. 